\title{
Reproductive tract infections: A set of factsheets
}

Population Council

Follow this and additional works at: https://knowledgecommons.popcouncil.org/departments_sbsr-rh

Part of the Demography, Population, and Ecology Commons, Family, Life Course, and Society

Commons, International Public Health Commons, Public Health Education and Promotion Commons, and the Women's Health Commons

How does access to this work benefit you? Let us know!

\section{Recommended Citation}

"Reproductive tract infections: A set of factsheets." Bangkok: Population Council, 1999. 


\title{
Reproductive Tract Infections: An Introductory Overview
}

\begin{abstract}
Reproductive tract infections are being increasingly recognized as a serious global health problem with impact on individual women and men, their families and communities. They can have severe consequences, including infertility, ectopic pregnancy, chronic pelvic pain, miscarriage, and increased risk of HIV transmission.
\end{abstract}

\section{Types of Infection}

Reproductive tract infections (RTIs) refer to three different types of infection which affect the reproductive tract:

Endogenous infections are probably the most common RTIs worldwide. They result from an overgrowth of organisms normally present in the vagina. Endogenous infections include bacterial vaginosis and candidiasis. These infections can be easily treated and cured.

Iatrogenic infections occur when the cause of infection (a bacterium or other micro-organism) is introduced into the reproductive tract through a medical procedure such as menstrual regulation, induced abortion, the insertion of an IUD or during childbirth. This can happen if surgical instruments used during the procedure have not been properly sterilized, or if an infection that was already present in the lower reproductive tract is pushed through the cervix into the upper reproductive tract.

Sexually transmitted infections (STIs) are caused by viruses, bacteria, or parasitic microorganisms that are transmitted through sexual activity with an infected partner. About 30 different sexually transmitted infections have been identified, some of which are easily treatable, many of which are not. HIV, the virus that causes AIDS, is perhaps the most serious sexually transmitted infection as it eventually leads to death. STIs affect both men and women, and can also be transmitted from mothers to children during pregnancy and childbirth.

\section{Global Burden}

RTIs are widespread. The World Health Organization estimates that each year, there are over 333 million new cases of curable STIs. In addition, UNAIDS calculates that in 2000 alone, 5.3 million people became infected with HIV. RTIs that are not sexually transmitted are considered even more common.

RTIs result in numerous serious consequences, particularly in women. Pregnancy-related complications, as well as congenital infections, can result from RTIs. Pelvic inflammatory disease (PID) can develop, and can cause infertility, ectopic pregnancy, and chronic pain. Recently, it has been shown that certain infections can increase the chances of HIV transmission. Unfortunately, symptoms and signs of many infections may not appear until it is too late to avoid such consequences and damage to the reproductive organs.

RTIs affect more than health. The morbidity associated with RTIs also affects the economic productivity and quality of life of many individual women and men, and consequently, of whole communities. 


\section{Prevention}

The best strategy to limit the harmful effects of RTIs is to prevent new infections. Each RTI should be prevented by methods related to its transmission routes.

Endogenous infections are easier to diagnose and treat than to prevent (although avoiding vaginal douching is recommended as it has been shown to increase the occurrence of bacterial vaginosis). Their consequences can be reduced through good access to adequate health care facilities and prompt health care seeking behavior.

Iatrogenic infections can be prevented by proper sterilization of medical instruments, adherence to sterile protocols during examinations, and screening or treatment for pre-existing infections before transcervical medical procedures are conducted.

Sexually transmitted infections can be prevented by the avoidance of sexual activity or the adoption of "safer sex" strategies, including mutual monogamy, non-penetrative sex, and the correct and consistent use of barrier contraceptive methods, particularly latex male condoms. The polyurethane vaginal sheath (female condom) is also considered to offer protection from STIs.

\section{Reproductive Tract Infection Factsheets}

For effective prevention and management of RTIs, accurate information is necessary, and should be widely available. These factsheets, produced by the Population Council with support from the Ford Foundation, aim to present up-to-date information related to RTIs in a clear and accessible manner. They are designed for health promoters, program managers, and service providers - and for anyone else involved in the dissemination of health information. In addition to this brief introduction to RTIs, there are 13 factsheets, addressing medical and social issues on a variety of topics related to RTIs.

\section{Factsheet Topics}

\section{Sites of Reproductive Tract Infections}

Definitions of Gynecological Morbidity for RTIs

Endogenous Infections of the Reproductive Tract

Iatrogenic Infections of the Reproductive Tract

Sexually Transmitted Infections: Basic Issues

Sexually Transmitted Infections: Treatment \& Management

Sexually Transmitted Infections and HIV/AIDS

Reproductive Tract Infections and Family Planning

Human Papilloma Virus and Cervical Cancer

Adolescents and Reproductive Tract Infections

Reproductive Tract Infections, Pregnancy and Children

Social Issues Related to Reproductive Tract Infections

Reproductive Tract Infections: An Annotated Bibliography 


\section{Population Council}

\section{Sites of Reproductive Tract Infections}

Reproductive tract infections can affect the external genital region and the reproductive organs. In both women and men, there are several potential sites of infection.

\section{Reproductive Tract Infections in Women}

The diagram ${ }^{1}$ below illustrates the reproductive tract of women. Infections in the area of the vulva, vagina, or cervix are referred to as lower reproductive tract infections. Infections in the uterus, fallopian tubes, and ovaries are considered upper reproductive tract infections.

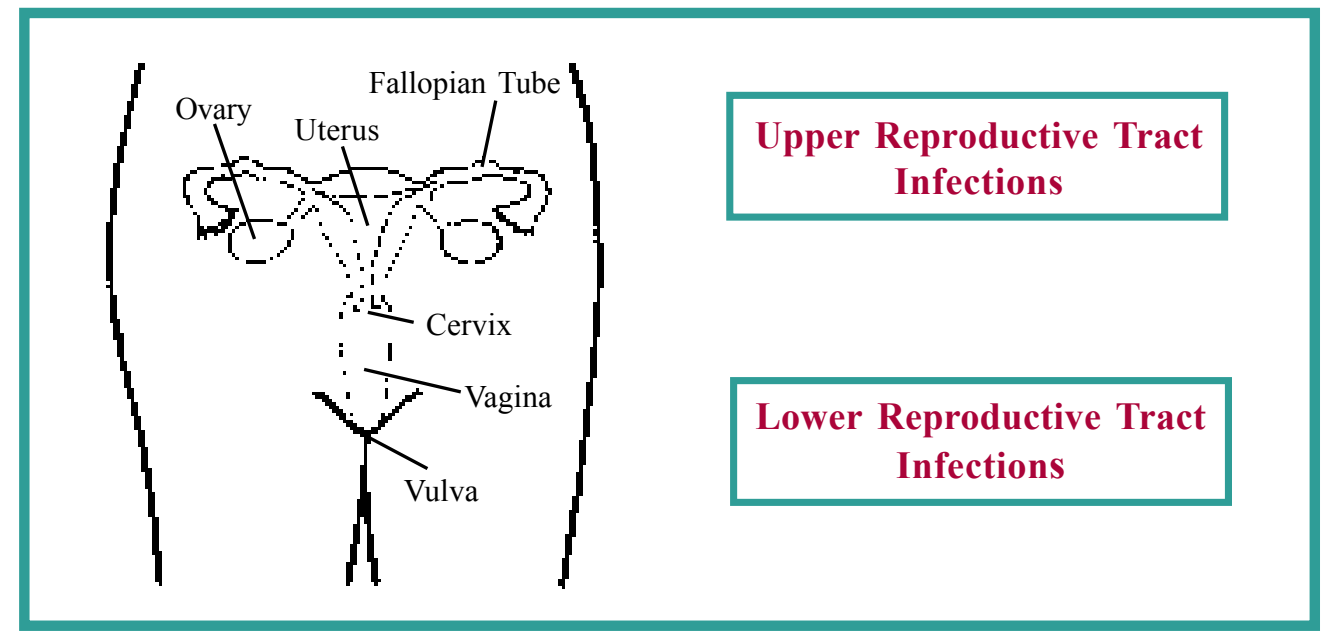

\section{Lower Reproductive Tract Infections}

\section{Vaginitis}

An RTI which affects the external genital area and lower reproductive tract in women is frequently referred to as vulvo-vaginitis, or simply vaginitis, indicating that the vulva and/or vagina become inflamed and sometimes itchy or painful.

Vaginitis is most commonly caused by endogenous infections, such as candida (thrush, yeast) or bacterial vaginosis, although certain sexually transmitted infections, such as trichomoniasis, can also commonly cause these symptoms and signs.

Although vaginitis generally is both treatable and less serious than cervical infections, when left untreated, some infections (e.g. several micro-organisms associated with bacterial vaginosis) may migrate up the reproductive tract. Infection of the upper reproductive tract is facilitated by transcervical procedures, such as menstrual regulation, abortion, or the insertion of an IUD. Prior infection of the fallopian tube also predisposes it to subsequent or chronic infection. Pelvic infections can have consequences far more dangerous than the initial vaginitis, such as ectopic pregnancy or infertility. 


\section{Cervical Infection}

Infection of the cervix can be caused by a variety of pathogens, particularly sexually transmitted infections such as gonorrhea and chlamydia.

Infections of the cervix are considered more severe than vaginitis because they much more commonly result in upper reproductive tract infection with its serious consequences. Unfortunately they are also more difficult to detect and they are frequently asymptomatic.

\section{Upper Reproductive Tract Infections}

The migration of infections into the upper reproductive tract, including the uterus, fallopian tubes, and ovaries tends to be considerably more severe than infections in the lower reproductive tract.

Upper reproductive tract infections are often a direct complication of lower reproductive tract infections, particularly sexually transmitted ones. Pelvic inflammatory disease (PID), for example, is one of the most serious consequences of gonorrhea or chlamydia. This can result in chronic abdominal pain, ectopic pregnancy, menstrual irregularities, and infertility as a result of scarring of the fallopian tubes.

Ectopic pregnancy, which can cause death, is a particularly serious complication, as it requires emergency interventions that are unavailable in many resource-poor settings.

Iatrogenic infections - caused by the introduction of bacteria into the normally sterile environment of the uterus through a medical procedure such as IUD insertion - can also result in serious, and occasionally life-threatening, upper reproductive tract infections.

\section{Reproductive Tract Infections in Men}

The diagram ${ }^{2}$ below illustrates the reproductive tract of men. In general, RTIs in men are easier to identify and treat, as they are more likely to be symptomatic.

RTIs generally begin in the lower reproductive tract (the urethra). If untreated, they may ascend through the vas deferens (sperm tube) to the upper reproductive tract (which includes the epididymis and testes, located in the scrotum, where sperm are produced).

Early signs of infection in men are from urethritis. This causes pain or burning upon urination and often a discharge from the tip of the penis. Ulcers and sores indicate other kinds of reproductive tract infections in men.

Infection of the upper reproductive tract can occasionally result in partial or complete blockage of the sperm ducts, and disorders in sperm production. This can cause low sperm counts in semen or abnormal sperm,

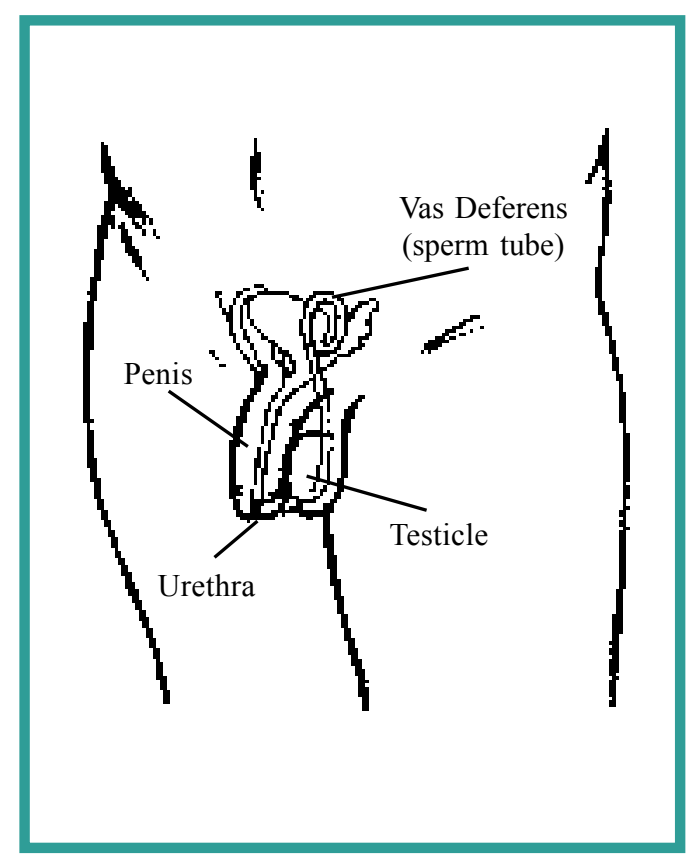
which contribute to male infertility. 


\title{
12 Population Council
}

\section{Definitions of Gynecological Morbidity for RTIs}

\begin{abstract}
Diagnosis and treatment of reproductive tract infections are complicated by confusion that surrounds the definitions and characteristics of various conditions. When different criteria are used for diagnosis, inconsistent prevalence rates and over-treatment can result. In order to avoid this confusion and improve management of such infections, standardized explanations drawn from the international literature are presented in this factsheet.
\end{abstract}

\section{Lower Reproductive Tract Infections}

\section{Infectious Causes of Vaginitis}

\begin{tabular}{|c|c|}
\hline Condition & Standard Clinical \& Laboratory Signs \\
\hline Candida & $\begin{array}{l}\text { Abnormal curd-like discharge. Fungi on wet preparation slide } \\
\text { with } 10 \% \text { Potassium Hydroxide }(\mathrm{KOH}) ; \mathrm{pH} \text { usually }<4.5\end{array}$ \\
\hline Bacterial vaginosis & $\begin{array}{l}\text { The Amsel Criteria: } \\
\text { A positive diagnosis is made if } 3 \text { of the following } 4 \text { criteria } \\
\text { are present: } \\
\text { - Speculum examination shows homogeneous vaginal discharge } \\
\text { - "Clue cells" are found on microscopy }(>20 \%) \\
\text { - Vaginal } \mathrm{pH}>4.5 \\
\text { - A "fishy" odor is produced when } 10 \% \text { Potassium Hydroxide } \\
\text { is added to vaginal secretions }\end{array}$ \\
\hline Trichomonas infection & $\begin{array}{l}\text { - Motile, bi-flagellated trichomonads seen on microscopy } \\
\text { - } \quad \text { Frothy discharge; } \mathrm{pH} \text { usually }>4.5\end{array}$ \\
\hline
\end{tabular}

\section{Cervical Infection}

Usually refers to bacterial infection of the endocervix, particularly with gonorrhea and chlamydia, although other infections can also occur at the cervix.

Due to lack of standardized and well-validated criteria, the term "cervicitis" is increasingly falling out of favor because it has often been used in reference to conditions that do not necessarily indicate cervical infection, including variants of normal conditions such as cervical ectopy.

On clinical examination, mucopus seen at the cervical os (opening) may indicate a higher likelihood of cervical infection. Seeing redness alone on the cervix does not reliably indicate cervical infection. 


\section{Upper Reproductive Tract Infections}

\section{Pelvic Inflammatory Disease (PID): Basic Criteria for Diagnosis}

Exclude surgical or pregnancy-related cause of symptoms.

Lower abdominal pain, signs of a lower genital tract infection, and cervical motion tenderness support a diagnosis of PID.

To increase specificity of the diagnosis (i.e. to avoid false positives) the following criteria can be added:

1. Temperature greater than $38^{\circ}$ Celsius

2. Palpable adnexal mass (finding a mass in a lower abdominal quadrant)

Many cases of pelvic inflammation are asymptomatic, despite causing damage to the reproductive tract that may result in infertility or ectopic pregnancy. Thus, while the presence of the above symptoms is helpful in confirming the diagnosis of PID, their absence does not rule it out.

\section{Non-Infectious Conditions}

\section{What is Cervical Ectopy?}

Cervical ectopy is a normal response of the cervix to hormonal changes resulting in redness around the cervical os. The red appearance is due to a change in the underlying type of tissue lining the mucosa, not to inflammation or infection.

This type of redness can often be seen in adolescents, pregnant women, and women using oral contraceptives. While ectopic tissue may be more susceptible to infection (for example, by chlamydia), its presence alone does not indicate infection.

\section{What is Cervical Erosion?}

Historically, this term generally refers to the same condition as cervical ectopy. It is no longer a recommended term.

\section{What is Cervical Friability?}

Cervical friability refers to easily induced bleeding of the cervix upon touch during a pelvic examination or cervical specimen collection. 


\title{
12 Population Council
}

\section{Endogenous Infections of the Reproductive Tract}

\begin{abstract}
Endogenous reproductive tract infections are a result of overgrowth of organisms normally present in the vagina. Worldwide, they are the most common cause of RTIs among women. These infections typically can be readily treated. If they are not treated, they can cause problems ranging from localized irritation to more serious consequences, such as pelvic inflammatory disease.
\end{abstract}

\section{Why Are They Important?}

Endogenous infections are very widespread and cause women varying degrees of discomfort and pain.

Common symptoms include vulvo-vaginitis (itching and pain in the external genital region and vagina), painful or uncomfortable sexual intercourse, and the presence of an abnormal discharge. Many women believe that such infections are normal and part of the female experience and, consequently, do not seek care due to shame or lack of information.

Numerous misconceptions surround endogenous infections. For example, many women believe, or are mistakenly told by medical practitioners, that their symptoms result from much more serious sexually transmitted infections. This can occur if the presence of inflammation or discharge caused by endogenous infections is confused with discharge produced by STIs such as gonorrhea or chlamydia. Indeed, many studies show that even experienced clinicians cannot reliably distinguish between vaginal discharge caused by sexually transmitted or endogenous infections. Aggressive syndromic management of vaginal discharge may result in considerable over-use of antibiotics, especially if women are routinely treated for suspected cervical infection.

Diagnosis of endogenous infections is possible with relatively simple laboratory procedures. Prompt health care-seeking behavior, therefore, combined with appropriate diagnosis and treatment of endogenous infections, could reduce the over-use of antibiotics.

\section{Causes and Consequences}

When the normal balance of vaginal flora is disturbed, an overgrowth of organisms can occur. Candidiasis and bacterial vaginosis are the most common resulting infections.

Candidiasis (referred to as thrush, or a yeast infection) is caused by the fungus candida. Some women appear to be naturally more prone to developing this type of infection for reasons that are not well understood. In addition, recent use of antibiotics, oral contraceptives that contain progesterone, or the presence of other conditions such as diabetes, pregnancy, or immune suppression (such as that caused by HIV, the virus that causes AIDS) can also increase a woman's chances of developing candidiasis.

\begin{tabular}{|l|}
\hline $\begin{array}{c}\text { Symptoms Experienced } \\
\text { by Women }\end{array}$ \\
- Thick, curd-like discharge \\
- Itching, soreness of the vulva \\
and vaginal area (vaginitis) \\
- Painful intercourse
\end{tabular}

\section{Signs Observed by Clinician}

- White, thick, curd-like discharge

- Redness of vulva, vaginal, and cervical tissue 
Bacterial vaginosis arises from an imbalance in the normal vaginal flora, which results in a loss of lactobacilli and can change vaginal $\mathrm{pH}$. Bacterial vaginosis is found more commonly among sexually active women although it is not clearly sexually transmitted and the treatment of male partners does not reduce recurrence. Symptoms include a thin gray, white or yellow/green discharge, and itching and soreness of the vulva and vaginal area. It can also remain asymptomatic.

Because bacterial vaginosis is an imbalance in the proportion of bacteria normally present in the vagina, diagnosis is made on the basis of a set of criteria, rather than detection of a specific causal organism. Most typically, the Amsel criteria (listed below) are used.

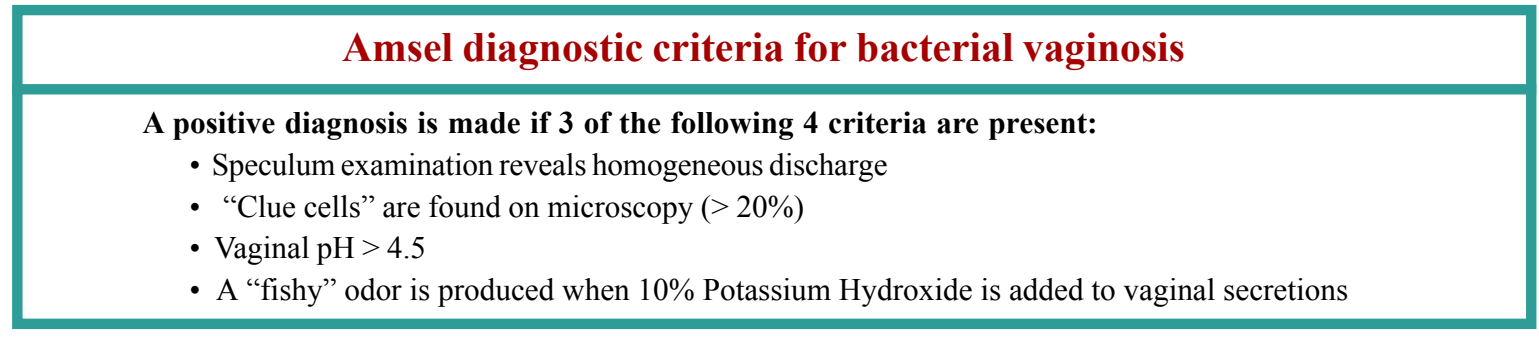

There is growing evidence that the presence of bacterial vaginosis, like a number of sexually transmitted infections, can increase the risk of sexual transmission of HIV. Preliminary data have also suggested that bacterial vaginosis may increase perinatal transmission of HIV.

If not treated, endogenous infections have the potential to cause greater complications. In pregnancy, these include premature rupture of the membranes, premature birth and consequent low birthweight. If introduced into the upper reproductive tract, micro-organisms associated with bacterial vaginosis may result in pelvic inflammatory disease which, in turn, can lead to ectopic pregnancy, infertility, and chronic pelvic pain.

\section{Prevention}

Vaginal douching should be avoided, as it can dry or cause imbalance in the vaginal environment and, hence, lead to bacterial vaginosis. The use of "drying" or "tightening" products can also cause imbalance and other harm.

Other health behaviors are also important. Women should be encouraged to use low-dose (as opposed to high-dose) oral contraceptive pills, avoid the unnecessary use of broad-spectrum antibiotics, and promptly seek health services at the onset of symptoms.

\section{Treatment}

Once a woman has an endogenous infection, it can be treated with oral anti-microbials or topical intravaginal creams.

Although endogenous infections are usually not sexually transmitted, they may be sexually associated possibly because sexual intercourse affects the vaginal flora (e.g. by increasing vaginal $\mathrm{pH}$ ). In some cases, men experience the itchiness and discomfort of candidiasis. 


\title{
12 Population Council
}

\section{Iatrogenic Infections of the Reproductive Tract}

\begin{abstract}
Iatrogenic reproductive tract infections are a result of bacteria being introduced into the normally sterile environment of the upper reproductive tract through a medical procedure, such as the insertion of an IUD, an induced abortion, or during delivery. The causal bacteria originate either from improperly sterilized examination or medical instruments (such as vaginal specula) or from endogenous or sexually transmitted infections already present in the lower reproductive tract.
\end{abstract}

\section{Why Are They Important?}

Because iatrogenic infections may affect the upper reproductive tract of women, they can result in extremely serious consequences. The uterus, endometrium, fallopian tubes, and ovaries can all be involved.

Pelvic inflammatory disease (PID) may develop and cause severe abdominal pain, pelvic abscess, menstrual disturbances, ectopic pregnancy, spontaneous abortion, premature birth, and infertility.

\section{Diagnosis and Treatment}

Many different bacteria can cause iatrogenic infection. Almost any infection already present in a woman's lower reproductive tract as well as sexually transmitted cervical infections, such as gonorrhea or chlamydia, can cause serious conditions when pushed into the sterile environment of the uterus. Bacteria on medical instruments can also introduce infection.

Depending on the specific nature of the condition, iatrogenic infections can often be treated successfully with antibiotics if they are diagnosed quickly. Unfortunately, many such infections receive attention only after they have caused irreparable damage, such as scarring or blockage of the fallopian tubes, or tissue damage.

If a woman has recently undergone a transcervical procedure, the following symptoms may indicate the presence of an iatrogenic infection.

\begin{tabular}{|ll|}
\hline & Warning Symptoms \\
\hline • & Pain in the pelvic region \\
\hline & Sudden high fever \\
- & Chills \\
- & Menstrual disturbances \\
- & Unusual vaginal discharge \\
- & Pain during intercourse \\
\hline
\end{tabular}




\section{Unsafe Abortion}

Although a variety of medical procedures can lead to the development of iatrogenic infections, unsafe abortion poses a particularly common risk. The vast majority of unsafe abortions take place in the developing world, and complications occur after $10-50 \%$ of them. ${ }^{1}$

Unsafe abortions are often sought if abortion is illegal, safe procedures are difficult to access or afford, or the woman is ashamed to seek care because she is young, unmarried, or the victim of sexual assault or coercion.

\section{Iatrogenic Infections Are Mainly Preventable}

Minimizing the frequency and consequences of iatrogenic infections depends on improving the quality and accessibility of good medical services. Unlike STIs, which rely primarily on behavior change for their prevention, avoiding iatrogenic infections centers on maximizing access to good quality care, and in particular the technical competence of health care providers. It also requires resources and supportive public policy measures and encouragement of prompt health care seeking behavior by individuals.

Medical institutions and health providers need adequate training and supervision to ensure that they carry out medical procedures with uncontaminated instruments and in a clean or sterile environment, as appropriate.

Providers should be aware of the relationship between infections that may be already present and the risk of iatrogenic infection. For example, clients should be checked for endogenous or sexually transmitted infections before insertions of the IUD to avoid bacteria being pushed into the uterus. Alternatively, women selecting the IUD should be encouraged to choose a different form of contraception if they consider themselves at risk of exposure to an STI.

Comprehensive reproductive health services should be made available, including the management of endogenous and sexually transmitted infections, to limit the risk factors for iatrogenic infection.

The possibility of unsafe abortion should be reduced through the provision of good quality, affordable and accessible abortion services, within the limits of the law. Quality family planning services also reduce the prevalence of abortion.

Women and their communities should be sensitized to the importance of seeking timely care for the symptoms of reproductive tract infection, and for the need to receive clinical care under safe and clean conditions.

Women who have undergone transcervical procedures, such as IUD insertion, abortion, or surgically-assisted delivery, should be made aware of warning signs that could indicate subsequent infection and be told to seek immediate care if needed. 


\section{Population Council}

\section{Sexually Transmitted Infections: Basic Issues}

Sexually transmitted infections are passed between people through sexual contact. Agents of infection include bacteria, viruses and other micro-organisms that can enter a person's urethra, vagina, mouth or anus. Some cause no symptoms at all, and some are easily treatable. Others result in severe long-term consequences and cannot be treated. HIV, the virus that causes AIDS, can lead to death.

\section{Why Are They Important?}

Over 30 different organisms can be transmitted through sexual activity. They can cause symptoms and consequences including the following: genital ulcers, inflammation, pain, infertility, ectopic pregnancy, spontaneous abortion, fetal wastage and premature delivery, and neonatal blindness and infection.

Sexually transmitted infections (STI) are now recognized as a serious global threat to the health of populations. The World Health Organization estimated in 1999 that as many as 340 million new cases of curable STIs occur each year, as follows:

\begin{tabular}{|c|c|}
\hline \multicolumn{2}{|c|}{ Annual new cases of curable STIs ${ }^{1}$} \\
\hline $\begin{array}{l}\text { - } 12 \text { million cases of syphilis } \\
\text { - } 62 \text { million cases of gonorrhea }\end{array}$ & $\begin{array}{l}\text { - } 92 \text { million cases of chlamydia } \\
\text { - } 173 \text { million cases of trichomoniasis }\end{array}$ \\
\hline
\end{tabular}

HIV/AIDS now represents a global pandemic. There is no cure for this STI, and it results in death. It is believed that 36.1 million people now live with HIV and AIDS, over $90 \%$ of them in developing countries. In 2000, about 5.3 million people were newly infected with HIV. ${ }^{2}$

\section{Prevention}

Because so many STIs go undiagnosed or have no treatments available, preventing their transmission is crucial. Risk can be reduced through the adoption of safer behaviors by individuals. Encouragement of these behaviors should then be incorporated into programs and policy.

\section{Individual Behaviors}

- Reducing the number of partners

- Being in a mutually monogamous relationship

- Substituting non-penetrative sex for intercourse

- Use of barrier contraception, such as male or female condoms

- Delaying age at marriage/first intercourse

- Treating STIs in self and partners

- Prompt and appropriate care seeking behavior

\section{Programs and Policy}

- Promoting "safer sex" prevention messages

- Making barrier contraceptives accessible/affordable

- Promoting delayed age at marriage/first intercourse

- Reaching vulnerable populations such as women and adolescents

- Promoting awareness of early treatment of curable STIs to decrease the time of infectiousness and reduce the risk of HIV transmission

\section{Relationship of HIV and Other STIs}

The transmission and acquisition of HIV are facilitated by the presence of other STIs. Ulcerative diseases increase the risk of HIV acquisition per sexual act most dramatically because genital ulcers and lesions allow easier entry of infectious particles. Inflammation caused by other STIs may also increase the viral load in genital secretions of those living with HIV infection, making transmission more likely.

${ }^{1}$ World Health Organization, 2001. Global Prevalaence and Incidencce of Selected Curable Sexually Transmitted Infections: Overview and Estimates. Geneva: WHO

2 UNAIDS, 2001. An Overview of the HIV/AIDS Epidemic. Fact Sheet, June 2001. www.unaids.org/fact_sheets/ungass. 


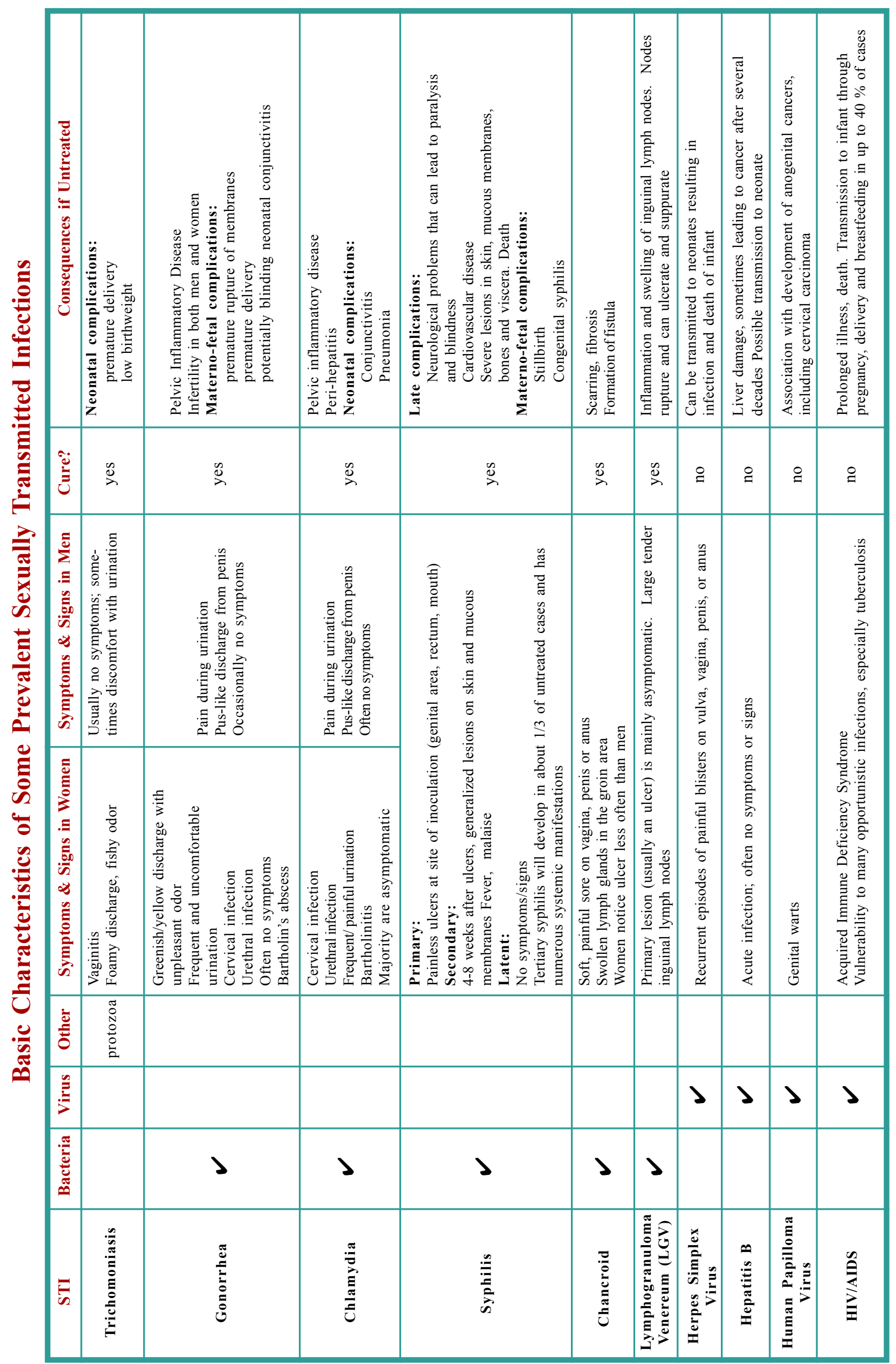




\title{
12 Population Council
}

\section{Sexually Transmitted Infections: Treatment \& Management}

\begin{abstract}
Diagnosis and treatment of sexually transmitted infections can be difficult, especially in situations where use of accurate laboratory testing is unavailable or prohibitively expensive. As a result, syndromic management techniques have been developed. This strategy has numerous advantages, particularly when used for symptomatic infections in men. However, disadvantages also exist and syndromic management is not able to address the serious and widespread problem of asymptomatic infection.
\end{abstract}

\section{Diagnosis and Treatment}

Timely diagnosis and effective treatment of STIs have always been important in limiting the morbidity and mortality associated with these infections.

Transmission and acquisition of HIV, the virus that causes AIDS, is facilitated by the presence of other STIs, and it is therefore even more important to provide services to treat these infections.

There have been two main approaches to diagnosis of STIs. They are laboratory and clinical. Below is a summary of their characteristics:

\begin{tabular}{|l|l|}
\hline \multicolumn{1}{|c|}{ Laboratory Diagnosis } & \multicolumn{1}{c|}{ Clinical Diagnosis } \\
\hline - $\begin{array}{l}\text { Microscopy or laboratory tests } \\
\text { (gram-stains, culturing etc.) }\end{array}$ & - $\begin{array}{l}\text { Relies on recognition of symptoms by the } \\
\text { patient and identification of signs from } \\
\text { clinician's medical experience }\end{array}$ \\
- Specific antibody or antigen tests & Unstandardized and often unreliable \\
- Tests need to be conducted by trained & - Inexpensive \\
technicians & - Can be combined with simple microscopy \\
Often requires sophisticated & where available \\
equipment or expensive supplies & Treatment can begin immediately \\
Waiting period for test results & \\
\hline
\end{tabular}

Although laboratory diagnosis is a more accurate way to identify STIs, it is not feasible in many parts of the world.

In resource-poor settings, therefore, clinicians often diagnose and treat according to their experience, with the use of simple microscopy or laboratory tests where available and affordable. The treatment regimens used are not always up-to-date, nor the most effective.

\section{Syndromic Management}

In an effort to standardize and improve clinical practice, the World Health Organization has developed the syndromic approach.

Diagnosis is based on the identification of syndromes, which are combinations of symptoms (reported by the client) and signs (observed during clinical diagnosis).

The recommended treatments are effective for all the diseases that could cause the identified syndrome. The most up-to-date drugs are recommended and dosages explained. Generally the treatment is provided during the patient's first visit, without the need to return to the clinic before initiating therapy.

Health education, prevention, counseling, condom promotion, the importance of treatment adherence, and partner referral are all recommended by the algorithms as an integral part of effective management. 
WHO has produced flowcharts and guidelines for the syndromic approach. The main syndromes addressed by this approach are genital ulcers in men and women, urethral discharge in men, vaginal discharge in women, and lower abdominal pain in women. Use of the syndromic approach has been tested and implemented in a variety of countries.

\begin{tabular}{l|l}
\multicolumn{1}{c|}{ Advantages } & \multicolumn{1}{c|}{ Disadvantages } \\
\hline - $\begin{array}{l}\text { Extremely effective for treatment of symptomatic } \\
\text { men with urethral discharge or men or women with } \\
\text { genital ulcers }\end{array}$ & $\begin{array}{l}\text { Can result in over-diagnosis and over-use } \\
\text { of antibiotics. For example, women with } \\
\text { vaginal discharge due to endogenous } \\
\text { infection may be erroneously classified as } \\
\text { having an STI }\end{array}$ \\
$\begin{array}{l}\text { Also effective when the vaginal discharge flowchart is } \\
\text { used for primary management of vaginitis (as opposed } \\
\text { to cervical infections) }\end{array}$ & $\begin{array}{l}\text { Sensitivity, specificity and positive } \\
\text { predictive values are poor when the } \\
\text { vaginal discharge flowchart is used for } \\
\text { management of cervical infections, } \\
\text { especially in low prevalence areas }\end{array}$ \\
$\begin{array}{l}\text { Laboratory diagnostics not necessary, } \\
\text { allowing for STI treatment in resource-poor settings } \\
\text { Primary health care workers can be trained to use } \\
\text { the technique }\end{array}$ &
\end{tabular}

One important limitation of syndromic management is that it cannot be used to find asymptomatic cases. This disproportionately affects women with STIs.

\section{Components of a Good Physical Exam}

Whichever approach to diagnosing and treating STIs is used, the process ought to include a thorough physical examination. Clients should be examined in a private space, and the clinician should always wear clean, disposable gloves.

Universal precautions should be taken to avoid transmission of any infection between clients and providers. All equipment used (such as a speculum) must be appropriately disinfected between uses.

Examinations of men and women should ideally include the following components:

\begin{tabular}{ll|l}
\multicolumn{1}{c|}{ Women } & \multicolumn{1}{c}{ Men } \\
\hline - Inspection of genitals, including separation & - $\begin{array}{l}\text { Inspection of genitals } \\
\text { of labia }\end{array}$ & $\bullet \begin{array}{l}\text { Retraction of foreskin to check for warts, } \\
\text { ulcers, and discharge in uncircumcised men }\end{array}$ \\
Abdominal and bimanual exams & Palpation of testicles and epididymis \\
- Where speculum and lamp are available, a pelvic exam
\end{tabular}

\section{Counseling}

All clients need to be informed about risk of STIs and other RTIs; common symptoms of infection; and prevention techniques, particularly use of the male and female condoms. If possible, condoms should be provided with demonstration using genital models.

Clients should also be encouraged to return for treatment if they do not get better and to seek treatment if they suspect they have contracted another RTI.

If the client has been diagnosed and treated for an STI, he or she needs to be told of the importance of partner referral. This is particularly important in the case of men, as their partners are more likely to be asymptomatic and thus unlikely to seek treatment.

Compliance with medical treatment should be emphasized. If a client does not complete the regimen, he/she could develop a resistant form of the infection that is not treatable.

Counseling should be more than providing information. It should empower people to make informed decisions about sexual activity. It should use a client-oriented approach, including a non-judgmental attitude and supportive presentation on the part of the provider. 


\title{
12 Population Council
}

\section{Sexually Transmitted Infections and HIV/AIDS}

\begin{abstract}
Sexually transmitted infections increase the likelihood that HIV, the virus that causes AIDS, will pass from one sexual partner to another. In turn, the presence of HIV increases vulnerability to STIs and prolongs the duration of infectivity. Prevention and management of STIs, therefore, have become a critical strategy for minimizing the impact of the HIV/AIDS pandemic.
\end{abstract}

\section{The STI - HIV Relationship}

It is now well-established that the presence of other sexually transmitted infections greatly facilitates the transmission and acquisition of HIV between sexual partners.

STIs which cause genital ulcers most significantly increase chances of HIV acquisition per sexual act the most. Other RTIs, however, can also increase the risk of HIV passing between sexual partners, particularly if they result in inflammation in the genital tract. The ways in which HIV transmission and acquisition are facilitated by the presence of infection are summarized below:

\begin{tabular}{|c|c|c|}
\hline Types of RTI & $\begin{array}{c}\text { Increased risk } \\
\text { of HIV transmission }\end{array}$ & $\begin{array}{l}\text { Way in which HIV } \\
\text { transmission is facilitated }\end{array}$ \\
\hline $\begin{array}{l}\text { Ulcerative STI } \\
\text { - Syphilis } \\
\text { - Chancroid }\end{array}$ & $3-9$ times & \multirow{2}{*}{$\begin{array}{l}\text { Because HIV is transmitted and acquired } \\
\text { through direct contact of bodily fluids, } \\
\text { the presence of open sores and blis- } \\
\text { ters/ulcers allows for greater such con- } \\
\text { tact and access to the bloodstream for } \\
\text { the virus }\end{array}$} \\
\hline Herpes Simplex Virus & 2 times & \\
\hline $\begin{array}{l}\text { Inflammation-causing STIs } \\
\text { - Gonorrhea } \\
\text { - Chlamydia } \\
\text { - Trichomoniasis }\end{array}$ & $3-5$ times & \multirow{2}{*}{$\begin{array}{l}\text { These infections increase genital shed- } \\
\text { ding of HIV infected cells. In addition, } \\
\text { urethral and endocervical infections } \\
\text { that cause inflammation allow for more } \\
\text { efficient exchange of infectious } \\
\text { particles }\end{array}$} \\
\hline Bacterial vaginosis & $1.5-2$ times & \\
\hline
\end{tabular}

\section{Vicious Circle of Infection}

The relationship between HIV and other STIs extends beyond the increased risk of HIV transmission.

An individual with HIV eventually suffers damage to the immune system, making him or her more susceptible to contracting other infections, including RTIs.

Furthermore, in an HIV-infected person, RTIs are more difficult to treat and cure. For example, lesions associated with syphilis can last longer. In the case of chancroid, the one-dose treatment has been found to be less successful among the immunosupressed. Recurrent episodes of Herpes simplex virus are also more frequent. Finally, endogenous fungal infections such as candida are common and difficult to cure.

As a result of the presence of other untreated STIs and some endogenous RTIs, an HIV-infected person is more likely to transmit HIV in subsequent unprotected sexual contact. 
The diagram below illustrates the vicious circle of HIV and STI co-infection:

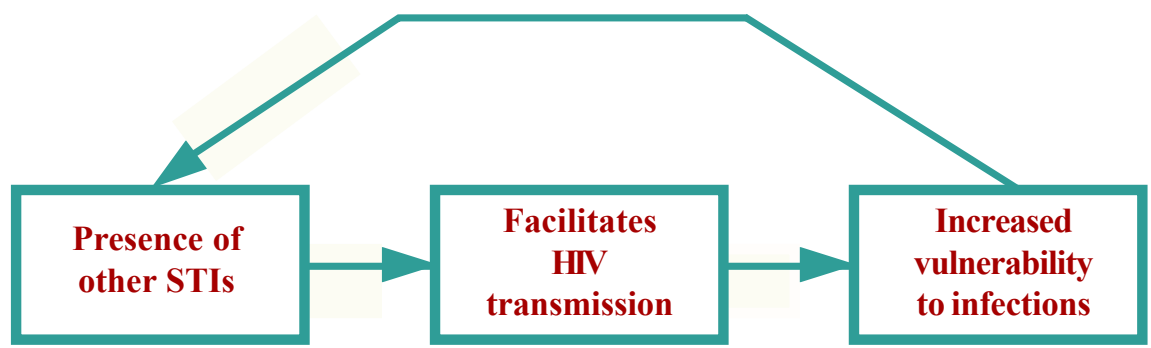

\section{Management of STIs as HIV Prevention}

To limit the morbidity and mortality associated with both STIs and HIV, prevention is crucial. Primary strategies for preventing the transmission of STIs are the same as those for HIV/AIDS.

Once contracted, however, many of the other sexually transmitted infections are curable whereas HIV is not. As a result, timely and appropriate management of other STIs can help curb the HIV pandemic.

One example of how widespread STI management has lessened the impact of the HIV pandemic comes from the Mwanza region in Tanzania. Over a two-year period, syndromic management of symptomatic STIs resulted in a $42 \%$ reduction in HIV incidence. ${ }^{1}$

There are three stages of HIV prevention through STI management. They apply to both individual behavior and health policy strategy. These are as follows:

\begin{tabular}{|c|c|c|c|}
\hline & 1. Reduce Exposure & $\begin{array}{l}\text { 2. Reduce Efficiency } \\
\text { of Transmission }\end{array}$ & $\begin{array}{l}\text { 3. Shorten Duration } \\
\text { of Infectivity }\end{array}$ \\
\hline $\begin{array}{l}\text { Individual } \\
\text { Behavior }\end{array}$ & $\begin{array}{ll}\text { - } & \text { Abstain from sex } \\
\text { - } & \text { Limit number of partners } \\
& \text { Remain in a mutually } \\
& \text { monogamous relationship }\end{array}$ & $\begin{array}{l}\text { - Substitute safer sexual } \\
\text { practices for risky sexual } \\
\text { behavior } \\
\text { - Use condoms }\end{array}$ & $\begin{array}{l}\text { - } \\
\text { - } \\
\text { for infectious symptoms } \\
\text { Abstain from sex during } \\
\text { treatment } \\
\text { - } \quad \text { Refer partners } \\
\text { Adhere to recommended } \\
\text { therapy }\end{array}$ \\
\hline $\begin{array}{l}\text { Health } \\
\text { Policy }\end{array}$ & $\begin{array}{ll}\text { - } & \text { Work to limit population } \\
\text { - } & \text { prevalence of STIs } \\
\text { - } & \text { Promote risk groups } \\
& \text { self-protection methods }\end{array}$ & $\begin{array}{l}\text { Promote safer sex } \\
\text { through active, } \\
\text { high-quality, gender- } \\
\text { sensitive information } \\
\text { campaigns } \\
\text { Make condoms easily } \\
\text { available (e.g. through } \\
\text { social marketing) }\end{array}$ & $\begin{array}{l}\text { Provide accessible STI } \\
\text { services (e.g. introduce } \\
\text { syndromic management } \\
\text { for symptomatic cases) } \\
\text { Encourage partner } \\
\text { referral and treatment }\end{array}$ \\
\hline
\end{tabular}




\title{
12 Population Council
}

\section{Reproductive Tract Infections and Family Planning}

\begin{abstract}
Reproductive tract infections are related to family planning issues in numerous ways. First, symptoms of infection may be attributed to contraceptive methods and might thus change attitudes toward contraception. Second, certain family planning methods may create risks for infection or worsen pre-existing RTIs. Finally, the family planning methods that best protect against unintended pregnancy are not the same that best prevent sexually transmitted infections. This affects the way services should be provided and how individuals and couples are counseled.
\end{abstract}

\section{Impact on Attitudes to Contraception}

Common symptoms of RTIs, such as abnormal vaginal discharge, pain during intercourse, or chronic pelvic pain, may be mistakenly perceived as side effects of contraception. In such cases, clients may discontinue use of their current method or abandon contraceptive use altogether.

\section{Associations between RTIs and Specific Contraceptive Technologies}

In general family planning methods actively protect against or have no effect on STIs. But some methods can predispose to infection or worsen a pre-existing infection. The following chart summarizes the relationship between contraceptive methods and RTIs:

\begin{tabular}{|c|c|c|}
\hline Method & Relationship to RTIs & What can be done? \\
\hline Oral contraceptive & $\begin{array}{l}\text { Can disrupt the balance of the } \\
\text { vaginal environment (particularly } \\
\text { high-dose pills), predisposing } \\
\text { development of candida (thrush, } \\
\text { yeast infection) } \\
\text { Does not protect from STIs } \\
\text { May decrease risk of PID }\end{array}$ & $\begin{array}{l}\text { Encourage use of low-dose } \\
\text { contraceptive pills } \\
\text { Suggest the use of barrier } \\
\text { methods for additional protection } \\
\text { against STIs }\end{array}$ \\
\hline Hormonal implant & $\begin{array}{l}\text { Does not protect from STIs } \\
\text { May decrease risk of PID }\end{array}$ & $\begin{array}{l}\text { Suggest the use of barrier methods } \\
\text { for additional protection against STIs }\end{array}$ \\
\hline Injectables & $\begin{array}{l}\text { Does not protect from STIs } \\
\text { May decrease risk of PID }\end{array}$ & $\begin{array}{l}\text { Suggest the use of barrier methods } \\
\text { for additional protection against STIs }\end{array}$ \\
\hline $\begin{array}{l}\text { Diaphragm and/or } \\
\text { spermicide }\end{array}$ & $\begin{array}{l}\text { Some partial protection against } \\
\text { cervical infection with bacterial } \\
\text { STIs; unknown protection from } \\
\text { viral STIs, including HIV }\end{array}$ & $\begin{array}{l}\text { Suggest the use of more effective } \\
\text { barrier methods for additional protection } \\
\text { against STIs }\end{array}$ \\
\hline $\begin{array}{l}\text { Male latex condoms and } \\
\text { polyurethane sheath } \\
\text { (female condoms) }\end{array}$ & $\begin{array}{l}\text { Effectively protect against STIs, } \\
\text { including HIV/AIDS when used } \\
\text { correctly and consistently }\end{array}$ & $\begin{array}{l}\text { Promote the correct and consistent } \\
\text { use of male latex and female } \\
\text { polyurethane condoms }\end{array}$ \\
\hline IUD & $\begin{array}{l}\text { Insertion with improperly } \\
\text { sterilized medical implements } \\
\text { or in a woman with an } \\
\text { untreated RTI can introduce } \\
\text { bacteria into the uterus, } \\
\text { causing iatrogenic infection } \\
\text { No protection from STIs }\end{array}$ & $\begin{array}{l}\text { Sterilize or high-level disinfect all } \\
\text { implements used for transcervical } \\
\text { procedures Screen IUD clients for } \\
\text { the presence of RTI; treat first } \\
\text { or provide a different method; consider } \\
\text { prophylactic antibiotic administration } \\
\text { Suggest the use of barrier methods } \\
\text { for additional protection against STIs }\end{array}$ \\
\hline $\begin{array}{l}\text { Female and male } \\
\text { sterilization }\end{array}$ & $\begin{array}{l}\text { Risk of iatrogenic (surgical) } \\
\text { infection. Does not protect from } \\
\text { STIs, although may decrease risks } \\
\text { of PID in women. }\end{array}$ & $\begin{array}{l}\text { Sterilize all implements used in surgery and } \\
\text { ensure adequate training of surgical pro- } \\
\text { viders. Suggest the use of barrier methods } \\
\text { for additional protection against STIs }\end{array}$ \\
\hline
\end{tabular}




\section{Sexually Transmitted Infections and Contraception}

Unfortunately, the methods that best prevent pregnancy are not the same methods that best prevent the transmission of sexually transmitted infections.

Methods most effective as contraception, as determined by typical use-effectiveness, include: male and female sterilization, hormonal implants, the IUD, injectables, and oral contraceptives. None of these methods prevent the transmission of sexually transmitted infection between sexual partners.

Methods most effective in preventing transmission of STIs are barrier methods, such as the male and female condoms. The diaphragm with spermicide may help prevent the transmission of cervical STIs although its impact on risk of viral and parasitic STIs is unclear.

Counselors and providers must help individuals and couples decide for themselves what the best approach is for them to prevent pregnancy and protect themselves from STIs.

One suggested strategy to help solve this dilemma is called dual protection. Dual protection is defined as "the protection from pregnancy and STIs/HIV through any of the following methods: condoms alone, condoms plus another contraceptive method, mutual monogamy among uninfected partners using contraception, abstinence, delayed onset of sex and avoiding all forms of risky sexual activity."

\section{Integration of Services}

Because of the close relationship between RTIs and contraception, there are many advantages to providing RTI services within family planning programs.

Family planning clinics are often the only or first contact women have with health services. If clients come with symptomatic RTIs and clinic staff are unprepared, a valuable opportunity to manage infections may be lost.

Family planning clients are sexually active women of reproductive age (15-44), a group that is also at risk of STIs. However, RTI services at a family planning clinic may not reach other atrisk groups such as adolescents, unmarried women, sex workers, menopausal women, and men.

Certain procedures, such as IUD insertion, should not be conducted on women with RTIs. Therefore, providers who may perform such procedures need to be aware of these relationships.

If screening and treatment are not feasible, family planning staff can assist with "self-assessment of risk." Through counseling about sexual behavior and history, women can themselves identify if they may be at high risk of contracting an STI and can thereby make better informed decisions about choice of contraceptives and disease protection.

1 Jeffrey Spieler, cited in USAID/Population Council, 2001. "Open Forum on Condom Promotion and Dual Protection: Meeting Report”, February 21, 2001. 


\section{Human Papilloma Virus and Cervical Cancer}

Human papilloma virus (HPV) is a sexually transmitted infection that has consistently been associated with the development of cervical cancer in women. Cervical cancer can be fatal if not identified in the early stages, and causes the death of 200,000 women worldwide each year. The incidence of new infections with HPV can be reduced through adoption of safer sexual practices. In addition, screening programs, while not affecting the prevalence of infection, can still reduce deaths from this cancer.

\section{What is HPV?}

The human papilloma virus (HPV) is a viral sexually transmitted infection. There are over 50 different subtypes of HPV and some of the most common cause genital warts.

Warts can appear on the cervix, inside the vagina, on the penis, on the inside of the urethra, and around the anus. Warts can be treated with local application of chemicals or cryotherapy. They cannot be cured, however, and may recur.

HPV can also be asymptomatic. Not all infected individuals develop genital warts. Even when asymptomatic, viral shedding of the infection and transmission to sexual partners are possible.

HPV subtypes 16, 18 and 31,33, 35 are commonly associated with the development of anogenital cancers in men and women. This includes cervical cancer and anal cancer.

\section{Relationship between HPV and Cervical Cancer}

In women, HPV subtypes 16 and 18 can cause precursor lesions (dysplasia) on a woman's cervix. These lesions can only be identified through screening programs carried out by trained staff. In many women, mild dysplasia regresses without any intervention or treatment. In a minority of cases, however, it will progress to moderate and severe dysplasia (larger, deeper lesions) and possibly to invasive cervical cancer.

This chart ${ }^{1}$ illustrates the stages leading to the development of cervical cancer:

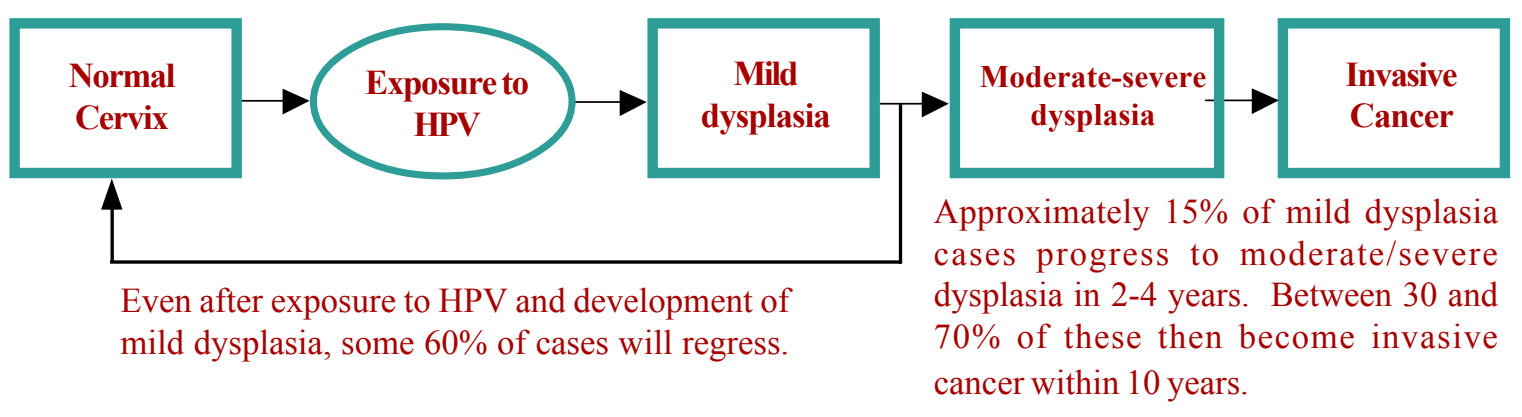

Although cervical cancer is the most common and serious consequence of HPV, other anogenital cancers are also considered to be associated with this STI. 


\section{About Cervical Cancer}

Cervical cancer is the most common cancer among women in the developing world and is often fatal if not diagnosed. If identified in the pre-invasive stage, however, it can usually be cured.

Each year, there are globally about 370,000 new cases of cervical cancer, of which some $80 \%$ occur in the developing world.

Factors thought to be associated with increased risk of cervical cancer include smoking, poor nutritional status, hormonal factors (such as delayed age at birth of first child), and the use of hormonal contraception. Young age at first intercourse and multiple sexual partners are also associated with higher risk of cervical cancer possibly because of greater exposure to a variety of STIs, including HPV.

Men's sexual behavior can put women at risk of developing cervical cancer. Women whose male partners have multiple sexual contacts can be exposed to STIs, including HPV, even if the women themselves are monogamous.

\section{Screening}

Screening offers the best method for identifying women with early (asymptomatic) lesions. Screening methods include visual inspection using acetowhite (acetic acid placed on the cervix will turn dysplastic areas white), or the use of Papanicolaou (Pap) smears.

While acetowhite staining offers immediate diagnosis, it is fairly nonspecific. Pap smears must be sent to qualified laboratories for analysis and results can take a long time. Pap smears can be performed where trained staff, speculums, slides and fixatives are available. This screening can only be effective in situations where adequate access to laboratories is possible, and where women can be contacted and recalled to receive the results within a reasonable time after the initial test.

Women at highest risk are those aged $35-50$. These women should be screened at least once, if possible. Ideally, Pap smears should be performed every three years. Screening programs have been shown to have impact, however, even in resource - poor settings where women can only be screened every five or even ten years.

\section{Management of Abnormal Pap Smears}

When women have mild dysplasia, they should be counseled to return for another screening test after six months, to see if the dysplasia has regressed or advanced.

In cases of moderate to severe dysplasia, women need to be referred to a higher level of medical services for review by a qualified gynecologist. They cannot be managed at the primary health care level. Explanation should be provided so that the women understand their condition and treatment needs. 


\title{
12 Population Council
}

\section{Adolescents and Reproductive Tract Infections}

\begin{abstract}
Sexually active adolescents and young people are particularly at risk for reproductive tract infections. They are vulnerable for both physical and social reasons and often suffer serious long-term consequences. As a group, however, they are often neglected by program efforts and health policy. As a result, they are less likely to be able to protect themselves from infection, or seek appropriate diagnosis and treatment.
\end{abstract}

\section{Who are Adolescents?}

Although increasingly recognized as a group that is particularly vulnerable to reproductive tract infections, adolescents are a difficult population to define. The World Health Organization refers to those aged 10-19 as adolescents, and 10-24 as young people.

Approximately one fourth of the global population is between the ages of 10 and 24 .

Regardless of the specific age categories used, however, adolescence generally refers to the time of transition between childhood and adulthood. Although the same physical changes related to maturation occur during this time period worldwide, there are significant differences in the expectations, norms, and meanings attached to adolescence between cultures.

\section{Why is Reproductive Health an Important Issue for Adolescents?}

Recent years have seen growing recognition of the reproductive health needs faced by young adults, particularly those who are unmarried. Unplanned pregnancies, sexually transmitted infections, and unsafe abortion all affect adolescents in large numbers. Additionally, about $50 \%$ of new HIV infections currently occur in people under 25.

Globally, as the age of marriage rises, adolescents are more likely to experience pre-marital sexual activity, despite the fact that there are often strong taboos on such behavior. Married adolescents, especially women, are also neglected. Many receive no reproductive health services until pregnancy or delivery, yet may be at risk of infection from their husbands who may have other sexual partners.

Adolescents who are sexually active often report that they did not expect to engage in sexual behavior when they first did. As a result, they are frequently unprepared to protect themselves from pregnancy or infection.

Few programs or policies specifically target adolescents. Often this neglect is deliberate and exists to limit unmarried adolescents' access to adequate information and comprehensive reproductive health services. As a result, adolescents are at risk of unplanned pregnancy and infections.

Young women often have older sexual partners. In some parts of the world, older men deliberately seek younger partners whom they believe are more likely to be free from infection than adults. 


\section{How Are Adolescents Vulnerable to Infection?}

A variety of medical and social factors put adolescents at particular risk for RTIs. The diagram below illustrates some of these determinants:

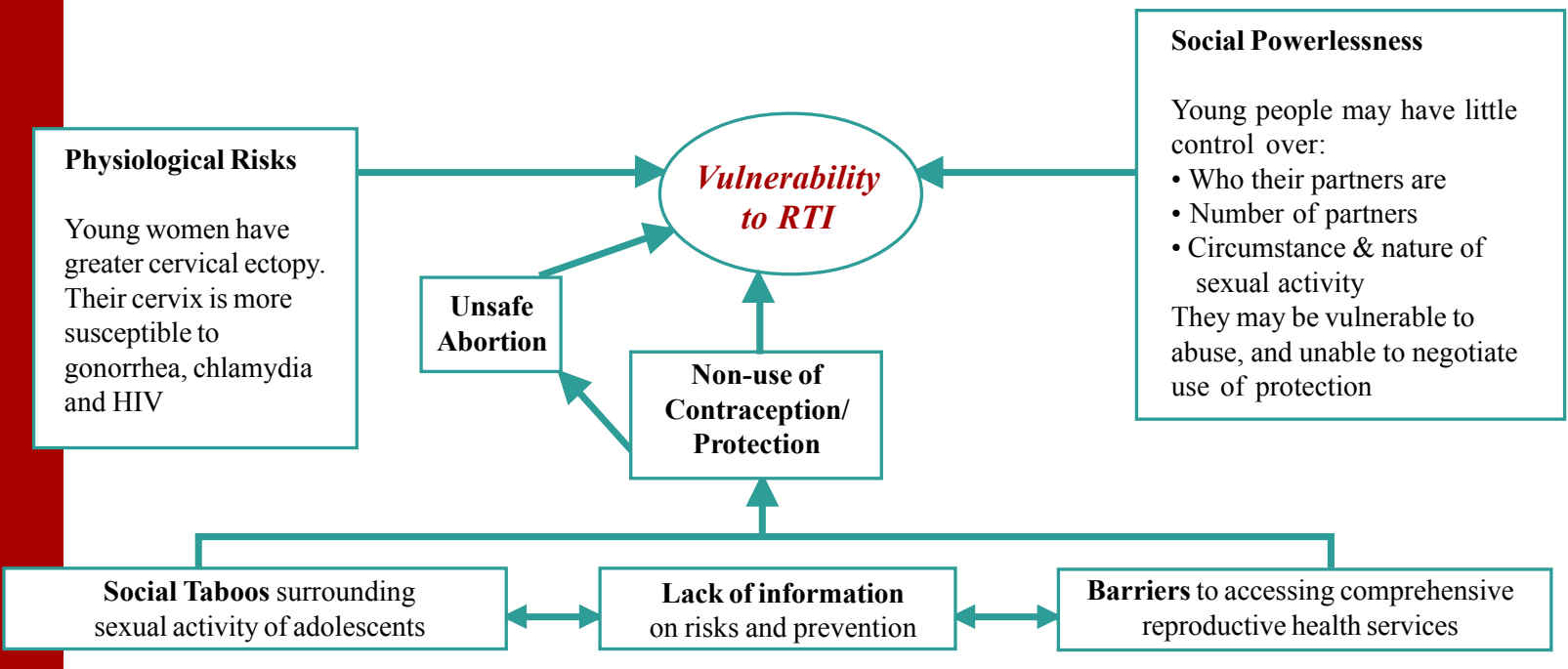

\section{Consequences:}

Because of barriers to receiving care, young people may be unable to seek timely and effective treatment for their infections.

Social taboos have tremendous impact. A young woman suffering from an RTI as a complication of an unsafe abortion may be ashamed to seek care.

Adolescents who do not control the circumstances of their sexual activity, such as victims of sexual coercion and abuse, are at risk of recurrent sexually transmitted infections even if they are able to seek treatment the first time.

Adolescents, particularly young women, who become infertile as a result of an RTI may be stigmatized or be abandoned in cultures where fertility is closely associated with women's perceived worth.

\section{What Can Be Done?}

Make programs accessible to young people, keeping in mind that different groups of adolescents will require differently tailored services (e.g. married versus unmarried adolescents).

Young people need accurate information about RTIs and their need to seek health care. Contrary to some popular belief, evidence from many countries shows that when appropriate sex education is provided, it does not encourage early sexual experience or increase sexual activity among adolescents. Indeed, sexual education may delay the age of sexual initiation, and is associated with safer sex behaviors.

Treat RTIs among adolescents and provide condoms along with extensive counseling for prevention. Ensure that such services are confidential and private so that they are attractive to adolescents. 


\section{Reproductive Tract Infections, Pregnancy and Children}

Reproductive tract infections can cause many adverse pregnancy outcomes, including spontaneous abortion, premature rupture of membranes, premature delivery and consequent low birthweight, and stillbirth. In addition, many RTIs can be passed between mother and infant during pregnancy and childbirth, resulting in serious morbidity and even death for the neonate. Infections can also lead to infertility.

\section{Effects on Pregnancy}

Almost all reproductive tract infections can cause adverse pregnancy outcomes. Sexually transmitted infections tend to have the most serious effects:

\begin{tabular}{|l|c|c|c|c|}
\multirow{2}{*}{\multicolumn{1}{|c|}{ RTI }} & \multicolumn{4}{|c|}{ Possible'Outcome } \\
\cline { 2 - 5 } & $\begin{array}{c}\text { Spontaneous } \\
\text { abortion }\end{array}$ & $\begin{array}{c}\text { Premature } \\
\text { rupture of } \\
\text { membranes }\end{array}$ & $\begin{array}{c}\text { Prematurity \& } \\
\text { Low } \\
\text { birthweight }\end{array}$ & Stillbirth \\
\hline Bacterial vaginosis & $\checkmark$ & $\checkmark$ & $\checkmark$ & $\checkmark$ \\
\hline Syphilis & & $\checkmark$ & $\checkmark$ & $\checkmark$ \\
\hline Gonorrhea & & & $\checkmark$ & \\
\hline Trichomoniasis & & & $\checkmark$ & \\
\hline Herpes Simplex Virus & & & $\checkmark$ & $\checkmark$ \\
\hline HIV/AIDS & & & $\checkmark$ & \\
\hline
\end{tabular}

The problem of syphilis during pregnancy is one of the most widespread. In developing countries, between 1-19\% of pregnant women test positive for syphilis. Routine screening using the rapid plasma reagin test (RPR) and subsequent treatment of the woman and her partner can minimize negative pregnancy outcomes. This type of screening has been shown to be extremely costeffective even in resource-poor settings and in areas of very low prevalence (i.e. $<0.1 \%$ ).

Any infection that can result in pelvic inflammatory disease (PID) (including iatrogenic infection) can predispose a woman to ectopic pregnancy, which is when the fertilized ovum implants outside the uterus, most often in the fallopian tubes. This is an extremely serious condition that can lead to maternal death. Appropriate intervention is often unavailable in resource-poor settings.

Gonorrhea and chlamydia can also increase the risk of postpartum infection.

Primary prevention of RTIs is the best method of reducing their effects on pregnancy. Screening for pre-existing infection can be done cost-effectively in some cases, most notably syphilis.

For syphilis screening, treatment of RTIs, and management of complications in pregnancy to be successful, pregnant women must seek and receive antenatal care services. Consequently, availability, accessibility, and active promotion of such services are crucial. 


\section{Vertical Transmission}

Many STIs can be passed from woman to child during pregnancy, childbirth, and breatsfeeding. This is known as "vertical transmission" and can have serious consequences for the health of the infant.

\begin{tabular}{|c|c|}
\hline RTI & Transmission \& Possible Effects for the Infant \\
\hline Syphilis & $\begin{array}{l}\text { - Congenital syphilis (in approx. } 1 / 3 \text { of cases). Can result in } \\
\text { infant death or long-term illness } \\
\text { - Transmitted during pregnancy }\end{array}$ \\
\hline Gonorrhea & $\begin{array}{l}\text { - Ophthalmia neonatorum. Can result in blindness } \\
\text { - Infection occurs during delivery through birth canal } \\
\text { Ocular prophylaxis (eye-drops given to newborn within } \\
\text { one hour of birth) can prevent Ophthalmia neonatorum }\end{array}$ \\
\hline Chlamydia & $\begin{array}{l}\text { - Ophthalmia neonatorum } \\
\text { - Neonatal pneumonia }\end{array}$ \\
\hline Hepatitis B & - Possible transmission during pregnancy \\
\hline Human papilloma virus & $\begin{array}{l}\text { - Child can suffer oral or anogenital warts } \\
\text { - Rare, serious complication: laryngeal papillomatosis }\end{array}$ \\
\hline Herpes simplex virus & $\begin{array}{l}\text { - Congenital herpes. Affects nervous system and can cause death } \\
\text { - Transmitted during pregnancy and through exposure during delivery }\end{array}$ \\
\hline HIV/AIDS & $\begin{array}{l}\text { Transmission can occur during pregnancy, delivery, } \\
\text { and through breastfeeding in up to } 30-40 \% \text { of infected mothers } \\
\text { Pediatric AIDS. Causes long-term illness and death. } \\
\text { Half of infected infants die within their first } 36 \text { months } \\
\text { Risk of vertical transmission greatly reduced through treatment with } \\
\text { zidovudine (AZT) or nevirapine (NVP) in the antenatal period }\end{array}$ \\
\hline
\end{tabular}

If left untreated, many of these conditions can cause neonatal disability or even mortality. Similarly, in situations where health care is inadequate or unavailable, pregnancy outcomes such as premature delivery and low birthweight can also increase the risk of neonatal death.

Preventing and curing reproductive tract infections could reduce both infant and maternal mortality.

If screening pregnant women for infection is not feasible, service providers can still prevent some of the harmful outcomes in infants, especially Ophthalmia neonatorum. Use of ocular prophylaxis at birth is highly successful and also cost-effective even in low prevalence settings.

Recent reommendations developed by UNAIDS, UNICEF and WHO still strongly emphasize the health benefits of breastfeeding for both infants and mothers. Recent data suggest that HIV-positive mothers should either exclusively breastfeed or exclusively provide breastmilk substitutes. Mixed feeding has the highest risk of HIV transmission ${ }^{1}$. Breast milk substitutes carry their own serious risks. Children born to HIV infected mothers should only receive substitutes if very specific conditions are met regarding the safety of supply and preparation of these substitutes. These conditions are difficult to ensure in many resource-poor settings.

\section{Limiting the Chances of Pregnancy}

Reproductive tract infections, especially those that are sexually transmitted, can cause damage to the reproductive tract that leads to infertility. For example, it is estimated that $50 \%$ of infertility in sub-Saharan Africa is due to RTIs.

Infertility has social as well as physical consequences. In cultures where fertility and childbearing carry important status and meaning, women with infertility may suffer ostracism, abuse, or abandonment. 


\title{
12 Population Council
}

\section{Social Issues Related to Reproductive Tract Infections}

\begin{abstract}
Reproductive tract infections have implications that extend beyond their effects on health. Numerous social factors play a role in determining the risks, reactions, and prevalence patterns in any population. These social issues differ between socio-cultural environments, but need to be identified and taken into account if education, prevention, and treatment programs are to achieve sustainable success.
\end{abstract}

\section{Framing the Questions}

The following table offers examples of social issues and processes that can influence how reproductive tract infections are transmitted, perceived, and addressed within a given community. It would be impossible to discuss all of the implications surrounding these issues, or indeed offer a comprehensive list of possible factors, in this factsheet.

The table suggests the kinds of questions that need to be framed in order to understand a population's experience of reproductive tract infections, and to identify the most appropriate ways to address them.

\begin{tabular}{|c|c|}
\hline $\begin{array}{l}\text { Influencing } \\
\text { Social Factor }\end{array}$ & Possible Relevant Questions \\
\hline Local legislation & $\begin{array}{l}\text { - What are the laws regarding abortion? } \\
\text { - Is coerced sex/abuse prosecuted? }\end{array}$ \\
\hline $\begin{array}{l}\text { Cultural values and } \\
\text { religious practices }\end{array}$ & $\begin{array}{l}\text { - What sexual taboos/restrictions exist? } \\
\text { - What are the prevalent attitudes toward sex education? } \\
\text { - How are sexual relations before/outside of marriage perceived } \\
\text { - What are the religious mess consistent with actual practice? } \\
\text { do they conflict with prevailing practices? } \\
\text { - Are family planning/disease prevention methods } \\
\text { available and acceptable? }\end{array}$ \\
\hline Economic structure & $\begin{array}{l}\text { - Is labor migration common? } \\
\text { - What kinds of inheritance laws exist? }\end{array}$ \\
\hline Gender relations & $\begin{array}{l}\text { - Do women have access to/control over financial resources? } \\
\text { - Is there a wide gap in power between men and women? } \\
\text { - Do women control if/when/with whom sexual activity occurs? } \\
\text { Is coerced sex prevalent? }\end{array}$ \\
\hline Marriage patterns & $\begin{array}{l}\text { - Is the society polygamous? } \\
\text { - At what age does marriage occur? } \\
\text { - Is there a wide gap in age between husbands and wives? }\end{array}$ \\
\hline Commercial sex & - Are commercial sex exchanges frequent? \\
\hline
\end{tabular}


To illustrate the process of identifying how social factors influence a community's experience with RTI's, gender, migration, and prevailing misconceptions about RTIs are discussed in greater detail.

\section{Gender}

Gender refers to the different social identities, roles, and responsibilities of men and women in their society. Differences in behavior, and the level of power between men and women can have an important impact on the risk of contracting RTIs.

- Women may have little choice in if, when, and with whom sexual activity occurs. They may be subject to coercion and abuse, or unable to negotiate safer sexual practices. As a result, their physiological vulnerability to infections is increased by social factors.

- Differing standards of behavior may mean that while men can seek sexual experience outside of marriage, women are expected to remain monogamous. Thus, even if their own behavior is not risky, women may be exposed to infections through their husband's behavior.

- If women do not have easy access to financial resources, they may be economically bound to risky partnerships or pressured to exchange sex for money or goods, increasing their exposure to infection.

- Physical consequences of infection, such as infertility, may be punished more severely in women, such as through loss of social status, abandonment or divorce. Women may also be blamed as carriers of sexually transmitted infections and suffer physical violence as a result.

\section{Migration}

Movement of populations, whether voluntary or forced, brings individuals and groups in contact with infections to which they may otherwise not have had exposure.

- Long term or cyclical labor migration that takes men or women away from their families often results in new infections returning with the workers to their families and home communities.

- Trade routes can bring mobile people into contact with one another and with each other's infections.

- Forced migration, such as in the cases of refugees, also brings populations with different disease prevalence together. Many refugee populations are composed mainly of women and children. Sexual assault, unwanted pregnancy, and commercial sex all increase, which can raise the risk of infections.

\section{Misconceptions}

RTIs, particularly those related to sexuality, touch on sensitive issues. Accurate information may not be widely available. As a result, many false beliefs are widespread.

- Women may believe that endogenous infections are a normal part of the "female experience" and not realize that they carry health risks and that treatment is available.

- Endogenous infections may be misinterpreted as sexually transmitted diseases, causing embarrassment, shame, and fear of seeking treatment if there are cultural associations between such infections and commercial sex work or infidelity.

- Misconceptions relating to HIV transmission are widespread and endanger communities' and individuals' ability to effectively protect themselves and to support people living with HIV/AIDS. People often believe that they can contract the virus through casual contact such as sharing eating utensils or clothing or being in the same room or workplace.

- Even where accurate information on HIV transmission is available, people may refuse to acknowledge their behavior as risky and deny personal vulnerability. 


\section{Population Council}

\section{Reproductive Tract Infections: An Annotated Bibliography}

Although not an exhaustive list, the following sources indicate where additional information can be found on the topics included in this set of factsheets.

\section{General Overview}

Adler, M., Foster, S., Grosskurth, H. et al (ed) (1998) Sexual Health and Health Care: Sexually Transmitted Infections. Guidelines for Prevention and Treatment. Health and Population Occasional Paper. London: Department for International Development.

Comprehensive summaries of research and best practices for interventions. This book, available from DfID, covers a wide range of related topics such as health promotion, medical treatments, assessment methodologies, relationship to HIV/AIDS, cost analysis, gender and other social issues.

Germain, A., Holmes, K., Piot, P., and Wasserheit, J. (ed) (1992) Reproductive Tract Infections: Global Impact and Priorities for Women's Reproductive Health. New York: Plenum Press.

Collection of articles addressing basic issues surrounding RTI in women, including possible intervention strategies and case study examples.

Tsui, A., Wasserheit, J., and Haaga, J. (ed) (1997) Reproductive Health in Developing Countries. Washington, D.C.: National Academy Press. In particular, Chapter 3 "Infection-free sex and reproduction."

This chapter gives an overview of all types of reproductive tract infections. It describes their transmission, consequences, biological and behavioral determinants, and presents prevention "best practice" strategies.

\section{Definitions of Gynecological Morbidity for RTIs}

Bulut, A., Yolsal, N., Filippi, V. and Graham, W. (1995) "In search of truth: Comparing alternative sources of information on reproductive tract infection," Reproductive Health Matters 3(5): 3139.

Description of a study conducted in Turkey which compared women's self-reported reproductive morbidity, clinical diagnosis, and laboratory tests. The lack of consistency between diagnoses using different criteria and the need for standardized definitions are discussed.

\section{RTIs and Reproductive Health}

Burns, A. August et al (1997) Where Women Have No Doctor: A Health Guide for Women. Berkeley: The Hesperian Foundation.

This book is a practical guide written in easy-to-understand language and includes numerous pictures, diagrams, and charts. It addresses topics in sexual and reproductive health as well as other women's health issues such as nutrition, disability and aging.

Family Care International (1998) Safe Motherhood Factsheets.

Produced by the Safe Motherhood Inter-Agency Group, this set of factsheets describes global trends, risks, interventions, and policy recommendations concerning maternal mortality. The set is available in two formats: a detailed version targeted at policy-makers and journalists; and an abbreviated version for general audiences. 
Hatcher, R., Rinehart, W., Blackburn, R. and Geller, J. (1997) The Essentials of Contraceptive Technology. Baltimore: Population Information Program, Center for Communication Programs, the Johns Hopkins School of Public Health.

This handbook for clinic staff was published as a supplement to the journal Population Reports and mainly describes family planning methods. It also contains a chapter on STIs and other infections of the genital tract, including their common signs and symptoms and treatment regimens.

World Health Organization (2001). Global Prevalence and Incidence of Selected Curable Sexually Transmitted Infections: Overview and Estimates. Geneva: World Health Organization.

This pamphlet focuses on four major curable STIs: chlamydia, gonorrhea, syphilis, and tricomoniasis. It provides basic facts about these infections, discusses global and regional trends, and notes aspects of infection or protection that affect specific populations such as pregnant women.

World Health Organization (2001). Guidelines for the Management of Sexually Transmitted Infections. Geneva: World Health Organization.

This book presents the updated recommendations for comprehensive management of STIs including HIV/AIDS. Its scope includes aspects of prevention, detection, and treatment, and the text also provides information on managing sexual partners and on STIs among children and adolescents.

\section{HPV and Cervical Cancer}

Program for Appropriate Technology in Health (1997) Planning Appropriate Cervical Cancer Control Programs. Seattle: PATH.

Collection of a variety of materials on the topic of cervical cancer control programs, including a set of factsheets, project summaries, annotated bibliography, and example presentation slides.

\section{Reproductive Tract Infections and Adolescents}

Family Health International (1997) Reproductive Health of Young Adults. Contraceptive Technology Update Series.

Information and training pack containing a general overview of the issues, slides, audience handouts, list of additional references, and article reprints.

McCauley, A.P. and Salter, C. (1995) “Meeting the Needs of Young Adults," Population Reports, Series J, No. 41. Baltimore: Johns Hopkins School of Public Health, Population Information Program.

This report offers a comprehensive look at the available evidence on reproductive health and adolescents. It presents international data, summaries of main issues, an overview and evaluation of programs and their successful components, and recommendations for future action.

\section{Reproductive Tract Infections, Pregnancy and Children}

Temmerman, M., Hira, S., and Laga, M. “STDs and Pregnancy," in Dallabetta, G., Laga, M., and Lamptey, P. (ed) Control of Sexually Transmitted Diseases: A Handbook for the Design and Management of Programs. AIDSCAP/ Family Health International.

This chapter discusses vertical transmission of STIs with a focus on syphilis and gonorrhea.

It offers recommendations for screening and treatment. 
Goldenberg, R., Iams, J., and Mercer, B. et al (1998) "The preterm prediction study: The value of new vs standard risk factors in predicting early and all spontaneous preterm births," American Journal of Public Health 88(2): 233-239.

This study is one of the first to introduce the association between bacterial vaginosis and premature rupture of the membranes. Various potential risk factors for spontaneous preterm birth were explored among approximately 3000 women.

\section{Social Issues Related to Reproductive Tract Infections}

Khattab, H. (1992) The Silent Endurance: Social Conditions of Women's Reproductive Health in Rural Egypt.Cairo: UNICEF and Population Council.

This is a collection of case studies from research conducted on reproductive morbidity among women in Cairo. It illustrates how socio-cultural conditions, including gender dynamics and family structure, influence perceptions of reproductive health and affect health care seeking behavior.

Institute for Development Training (1993) "Reproductive Tract Infections" The Training Course in Women's Health, Module 9, $2^{\text {nd }}$ Edition.

Manual for health workers in resource - poor settings. The curriculum includes introduction to various RTIs and STIs, treatment regimes, and review questions.

\section{STIs, Including Relationship to HIV/AIDS}

Celum, C., Wilch, E. Fennel, C., and Stamm, W. (1994) The Practitioner 's Handbookfor the Management of Sexually Transmitted Diseases: $2^{\text {nd }}$ Edition. Seattle: Health Sciences Center for Educational Resources, University of Washington.

This manual is organized by disease syndrome. It provides algorithms and summary descriptions of diagnosis and treatment of conditions. Guidelines for treatment, laboratory methods, and diagnostic tests, as well as photographs illustrating specific cases of morbidity, are also included.

Dallabetta, G., Laga, M., and Lamptey, P. (ed) Control of Sexually Transmitted Diseases: A Handbook for the Design and Management of Programs. AIDSCAP/ Family Health International.

This book contains fifteen chapters that address programmatic issues related to STIs.

Grosskurth, H., Mosha, F., Todd, J., et al. (1995) “Impact of improved treatment of sexually transmitted diseases on HIV infection in rural Tanzania: randomised controlled trial" Lancet 346: 350-6.

Description of the study in the Mwanza region of Tanzania in which aggressive syndromic management of STIs was found to decrease the incidence of HIV by $42 \%$ in the intervention communities.

Lande, R. (1993) “Controlling Sexually Transmitted Diseases," Population Reports Series L, No. 9. Baltimore: Johns Hopkins School of Public Health, Population Information Program. Comprehensive summary of issues related to STIs, including signs and symptoms, prevention measures, relationship to HIV/AIDS, treatment and management. In-depth discussion of the WHO syndromic management approach; poster of WHO flowcharts accompanies the report.

World Health Organization (1991) Management of patients with sexually transmitted diseases: Report of a WHO Study Group Geneva: WHO Technical Report Series, No. 810.

Explanation and introduction to WHO syndromic management diagnosis and treatment approach. 


\section{Reproductive Tract Infections and Family Planning}

Cates, W. Jr. and Stone, K. (1992) "Family Planning, Sexually Transmitted Diseases and Contraceptive Choice: A Literature Update I," Parts I \& II. Family Planning Perspectives 24(2): 75-83 and 24(3): 122-128.

Discussion of the relationship between STI prevention and contraception, including findings from different program contexts regarding counseling and success of dual protection strategies.

Elias, C. and Leonard, A. (1995) "Family Planning and Sexually Transmitted Diseases: The Need to Enhance Contraceptive Choice," Current Issues in Public Health 1: 191-199.

Outline of the issues related to contraception and STI prevention, including the difficulties in integrating services. Presents detailed chart on specific contraceptive methods and their relationship to RTI and STI risks.

\section{Useful Web Sites}

American Social Health Association at www.ashastd.org

Provides links to other sites relating to STIs. Online newsletters, information, and a glossary of relevant terms are also available.

Global Reproductive Health Forum at Harvard at www.hsph.harvard.edu/Organizations/ healthnet/

This site is designed to encourage interactive participation and critical, democratic discussions of reproductive health and gender on the internet. It offers information, research papers, and opportunities for comment.

\section{Joint UN Program on AIDS (UNAIDS) at www.unaids.org}

The latest information on HIV/AIDS statistics is available on this site as are UNAIDS press releases, publications, and recommendations.

National Library of Medicine (USA) at www.nlm.nih.gov

Offers free access to Medline, the bibliographic database for literature published in current, peer-reviewed biomedical journals.

\section{Reproductive Health Outlook website at www.rho.org}

Provided by the Program for Appropriate Technology in Health (PATH) this site provides information, links, and interactive message boards on numerous reproductive and sexual health topics.

Safe Motherhood Inter-Agency Group at www.safemotherhood.org

Offers information on safe motherhood recommendations for programs and policies.

US Center for Disease Control, Division of STD Prevention at www.cdc.gov/nchstp/dstd/ dstdp.html

Although primarily designed for use within the United States, this site also offers a series of factsheets on sexually transmitted infections, treatment guidelines, and training opportunities. The Division of Reproductive Health also has its own site at www.cdc.gov/nccdphp/ 